\title{
LA TRINIDAD NO SANTA: delicuencia transnacional, corrupción y terrorismo ${ }^{1}$
}

\author{
Louise Shelley
}

Los tradicionales grupos de delincuencia transnacional y sus homólogos más recientemente formados tienen relaciones muy diferentes con el Estado y con el terrorismo. ${ }^{2}$ En países creados desde hace mucho tiempo, los grupos delictivos de mayor antigüedad se han desarrollado junto al aparato estatal y dependen de las estructuras institucionales y financieras existentes para mover sus productos e invertir sus ganancias. Con excepción de Colombia, las grandes organizaciones delictivas que tienen estabilidad, raramente se relacionan con grupos terroristas, ya que sus intereses financieros a largo plazo requieren la preservación de las estructuras del Estado (Thomi, 1995). A través de la corrupción y el ingreso a la economía lícita, estos grupos minimizan el riesgo de ser sometidos a acciones judiciales y, por lo tanto, no temen el poder de las instituciones del Estado. Por el contrario, los grupos más recientes

* Professor-Doutor da American University. Brandywine Street, Suite 300. Washington, D.C. 20016-8178. Telefone: 202-8852830.traccc@american.edu

${ }^{1}$ Este artigo foi traduzido do inglês para o espanhol por Arelis Madero.

${ }^{2}$ La importancia de considerar el Estado y la evasión de las leyes del Estado es tratada en: McC. Heyman; Smart (1999, p. 1-24). de delincuencia transnacional, frecuentemente originados en situaciones pos-conflicto, prosperan en un estado de caos y conflicto constante. En éstas regiones donde la economía clandestina predomina, los grupos de delincuencia organizada son los actores que dominan esa economía.

En las regiones ingobernables, los nuevos grupos de delincuencia organizada actualmente están forjando alianzas con las organizaciones terroristas; y dado que los grupos delictivos y las organizaciones terroristas no poseen estrategias financieras ni horizontes políticos a largo plazo, tampoco tienen que temer a los regímenes corruptos y el control social inefectivo que caracterizan las regiones en conflicto.

Los grupos de delincuencia organizada se han desarrollado en Asia, América Latina, África, Europa y Estados Unidos; ninguna región del mundo y ningún sistema político han impedido su surgimiento o tenido éxito en eliminarlos. ${ }^{3}$ Por consiguiente, los grupos internacionales de delincuencia localizados en China, Japón, Colombia, México, Nigeria, Rusia, Italia y Estados

${ }^{3}$ Para un análisis ampliado de este tema, véase Shelley (1995, p. 463-489). 
Unidos han perdurado, pese a la acción represiva de los gobiernos fascistas en Italia y la Unión Soviética, de los sistemas comunistas chinos y del FBI en Estados Unidos. Han sobrevivido porque frecuentemente ofrecen servicios al Estado; han corrompido, o desarrollado relaciones de complicidad con las organizaciones del Estado; o han evolucionado hacia la realización de funciones específicas dentro de la comunidad (Pezzino, 1990).

Los grupos más recientes de la delincuencia transnacional han proliferado en cantidad y número de miembros desde finales de la Guerra Fría. Tales grupos, surgidos en la antigua Yugoslavia, Sri Lanka, Afganistán o en muchos de los Estados sucesores de la antigua Unión Soviética, no fueron conocidos internacionalmente antes de los años 1990. Actualmente, operan transnacionalmente, vendiendo drogas, armas, personas y contrabando. En sus actividades ilícitas, estos nuevos grupos delictivos difieren muy poco de los grupos más establecidos. En sus entornos, sus actividades criminales son disfrazadas dentro de la economía clandestina más grande. Sin embargo, a diferencia de sus contrapartes en Estados Unidos, Japón o Italia, los nuevos grupos de delincuencia organizada no obtienen utilidades de los contratos estatales (Della Porta, 1992, p. 312-328). Tampoco lavan grandes cantidades de dinero a través de las instituciones financieras y proyectos inmobiliarios (Taylor, 2002). En su lugar, estos grupos florecen dentro de la economía clandestina, ante la ausencia de un Estado efectivo y la presencia de una corrupción endémica.

Los nuevos grupos de delincuencia organizada más frecuentemente relacionados con el terrorismo no tienen interés en promover un Estado seguro. De hecho, promueven la injusticia, pues, a través de la prolongación del conflicto, aumentan sus ganancias (Berdal; Malone, 2000). No hay falta de incentivos de su parte para colaborar con los terroristas, ya que no buscan estabilidad, ni tampoco un Estado que los controle. El punto en el que confluyen la delincuencia transnacional, el terrorismo y la corrupción es extremadamente amenazante para el orden internacional. La naturaleza arraigada de las estructuras de la red delictiva en las comunidades locales y la incapacidad de las fuerzas militares, tanto domésticas como internacionales, así como las organizaciones policiales, para controlar sus actividades, los hacen un peligro creciente. El fracaso de la comunidad internacional en reconocer la centralidad de esta trinidad no santa permitió que éste nexo floreciera en los años 1990 y a comienzos de este siglo.

\section{EL INCREMENTO Y LA DIVERSIFICACIÓN DE LOS GRUPOS DE DELINCUENCIA TRANSNACIONAL}

El fin de la Guerra Fría y el aumento de la globalización han contribuido simultáneamente con el crecimiento de los nuevos grupos de delincuencia transnacional. Estos grupos se han convertido en actores cada vez más importantes dentro de la economía ilícita global, concentrados en los estados débiles, mientras que la intervención del Estado en los países con gobiernos fuertes ha frenado el crecimiento de la mafia en Italia y Estados Unidos, los boryokudan en Japón, y ha contribuido con el colapso del Cartel de Medellín en Colombia (Reuter, 1995, 1996).

El incremento de la globalización después de la caída de la Unión Soviética ha contribuido con el surgimiento de nuevos actores de la delincuencia transnacional. El incremento del transporte internacional, las comunicaciones y la movilidad, ha proporcionado a los grupos más pequeños un mayor acceso a los mercados internacionales. Más aún, la globalización ha empobrecido y marginalizado a muchas comunidades en los países en vías de desarrollo, obligándolas a involucrarse en actividades ilícitas para sobrevivir. Con el colapso de los precios de las materias primas en la economía globalizada, muchos productores, aconsejados por traficantes de drogas, han pasado al cultivo de drogas para sobrevivir económicamente. Su único medio de supervivencia es entrar a la economía clandestina. Otros han dejado sus comunidades, movilizándose por vas- 
tas distancias en busca de empleo para mantener a sus familias (Bales, 2000). Sin poder ingresar legalmente a los países desarrollados de Europa Occidental y Estados Unidos, la red de tráfico de personas, liderada por grupos de delincuencia organizada, ha surgido para satisfacer la demanda creciente. Por consiguiente, el incremento y la diversificación del mercado de la droga, el contrabando y el tráfico de humanos, en este período, son una consecuencia del desarrollo político y económico de las décadas recientes.

Con el fin de la Guerra Fría, cesó el conflicto entre las superpotencias y emergió una era de conflictos regionales más pequeños en África, en los países balcánicos y en toda la antigua Unión Soviética. ${ }^{4}$ Grupos poderosos de delincuencia organizada se han materializado en estas nuevas zonas de conflicto y sus actividades criminales les han proporcionado los fondos para la compra de armas y el pago de sus soldados. $\mathrm{Al}$ operar internacionalmente, estos grupos han explotado los mercados ilícitos de drogas, personas, armas y diamantes (Campbell, 2002). Por su codicia, no están prestos ni dispuestos a resolver tales conflictos. Es en éste sentido, en el cual sus intereses convergen con los intereses de los terroristas. Así, los terroristas, quienes persiguen destruir el sistema existente por razones políticas, comparten un objetivo común con los grupos criminales. Ambos prosperan y se desarrollan en medio de la violencia y el desorden del Estado.

Los nexos entre la delincuencia transnacional y el terrorismo son más evidentes en el caso del terrorismo islámico. Sin embargo, el vínculo entre la delincuencia transnacional y el terrorismo no se limita exclusivamente a los grupos yihadistas, ${ }^{5}$ sino

\footnotetext{
${ }^{4}$ Reno, op. cit., p. 43

${ }^{5}$ Se entiende como yihadistas a los grupos cuyo interés es la persecución del Yihad. Yihad es un concepto esencial del Islam, cuya traducción literal es esfuerzo. Suele aparecer en el Corán como "esfuerzo en el camino de Dios", en el sentido de hacer reinar los derechos de Dios, es decir, defender el Islam. Por esta razón se le asemeja con el término "guerra santa". La defensa del Islam, de los musulmanes o de sus países frente al enemigo externo puede, efectivamente, adquirir el carácter de lucha militar o "guerra santa". Sin embargo, yihad es también la predicación pacífica, la defensa dialéctica del Islam, la explicación de la doctrina islámica a los no musulmanes, etc (Nota del Traductor).
}

que también existe en otras regiones en conflicto, como en Perú, con el Sendero Luminoso, y en Nepal, con los insurgentes maoístas. El negocio de la droga en Afganistán financia a los talibanes y las actividades de la delincuencia organizada han mantenido el conflicto checheno y la violencia en Kosovo (Alliot-Marie, 2004, p. A27; Addullaev, 2004; Andreas, 2004). En estas regiones, la delincuencia organizada está relacionada con otras partes del mundo, como, por ejemplo, las drogas de Afganistán, que son distribuidas en Europa por grupos locales de delincuencia organizada o el tráfico de mujeres kosovares albanesas desde la antigua URSS hacia Europa Occidental. Un nexo similar existe entre los soldados quienes han participado en estos conflictos. Los terroristas entrenados en Chechenia han sido arrestados por terrorismo en Francia y los individuos quienes lucharon en Afganistán posteriormente han sido combatientes en los países balcánicos y en Chechenia. El delito internacional y las redes terroristas se cruzan particularmente en estas zonas de conflicto, donde las organizaciones policiales y de control sobre las fronteras son corruptas y, en algunos casos, cómplices completos de los grupos delictivos.

\section{EL DELITO TRANSNACIONAL Y EL ESTADO}

La mafia italiana es el prototipo para los conceptos de delincuencia organizada. Aunque la mafia se desarrolló en Sicilia a mediados del siglo XIX, sus orígenes van hacia lo profundo de la sociedad siciliana (Catanzaro, 1992). De modo similar, existen grupos tradicionales de delincuencia internacional en muchas otras partes del mundo. Como ejemplo, están los japoneses Yakuza, quienes alcanzaron prominencia internacional en el período posguerra, pero cuyos orígenes datan de los años 1600 (Kaplan; Dubro, 2003). Lo mismo puede decirse de la Sociedad Secreta China, quienes operaron particularmente en el Sur de China, cuyos orígenes se encuentran en la historia china del siglo XIX (Booth, 1999). A través de corromper, y algunas veces penetrar el Estado, estos grupos delictivos 
crean una relación de complicidad, gastando cantidades significativas de capitales humanos y financieros para generar una influencia sobre el Estado. Así, pueden contribuir con campañas políticas, postular candidatos para cargos públicos o votar en bloque para influenciar el proceso electoral, tal y como ha ocurrido en Italia. En Colombia, antes del nacimiento de las guerrillas a gran escala, el conocido traficante de drogas Pablo Escobar se postuló para el parlamento y creó un partido político (Abbadinsky, 2002, p. 246-247).

Con frecuencia, estos grupos delictivos son muy nacionalistas. En Japón, los Yakuza sirvieron al emperador antes de la Segunda Guerra Mundial, suprimiendo a sus oponentes políticos. Su alto grado de nacionalismo los ha hecho aliados de la policía conservadora japonesa, neutralizando el control sobre sus actividades hasta muy recientemente. Así mismo, durante la Segunda Guerra Mundial, algunos elementos de la mafia en Estados Unidos custodiaron los muelles para prevenir el sabotaje por parte de los alemanes. En otro caso, la mafia contemporánea en Sicilia rompió relaciones con un grupo específico de delincuencia organizada albanesa cuando se les informó que éstos eran terroristas. Es muy claro que los grupos delictivos tienen intereses coincidentes con la habilidad del Estado por mantener su estabilidad a largo plazo.

Esta relación simbiótica ha resultado ser valiosa para el auge de los grupos de delincuencia organizada tradicionales. Los grupos de delincuencia organizada en Italia y Japón se han beneficiado enormemente del proceso de recuperación posguerra de sus países. Estos grupos han sacado ganancias de valiosos contratos públicos de construcción, posiblemente tanto como de sus actividades ilícitas. Por lo tanto, el desarrollo económico del Estado es de primordial importancia para éstos grupos, ya que son parásitos de la economía del Estado y de las instituciones financieras.

Sin embargo, los nuevos grupos de delincuencia transnacional sacan provecho del caos de la guerra y los conflictos duraderos. Éstos no tienen interés en fortalecer el Estado, por el contrario, sus ganancias son hechas a través de la desestabilización del Estado y sus estructuras. El declive de la importancia del Estado-Nación en décadas recientes ha fomentado estas nuevas formas de grupos de delincuencia transnacional. Existen razones importantes por las cuales estos nuevos grupos del delito transnacional comparten intereses comunes con los terroristas. La relación entre delincuencia transnacional y terrorismo se extiende más allá de un matrimonio por conveniencia que genera ganancias o proporciona logística: llega hasta el fondo de la relación entre los grupos delictivos y el Estado. Los nuevos grupos de delincuencia transnacional, que con frecuencia operan regionalmente, aprovechan las fronteras permeables y las instituciones disfuncionales del Estado, donde el territorio está fuera del control del Estado central. Al explotar las diferencias entre las normas legales y procedimientos entre diferentes jurisdicciones, estos se capitalizan sobre el hecho de que los controles legales tienen su fundamento en el Estado. Con frecuencia arraigado en la sociedad huésped, este tipo de grupo delictivo no se basa en la familia, ni tampoco es estructurado rígida y jerárquicamente como la mafia. En su lugar, proviene de diferentes niveles de la sociedad que contribuyen de distinta manera a la perpetuación de la actividad criminal. Este patrón ha sido observado en los países balcánicos, así como en el Cáucaso y en Afganistán.

En muchas regiones en conflicto, la economía clandestina es la única economía que funciona. En los países balcánicos, el contrabando de cigarrillos en pequeña escala ha mantenido a muchos individuos de bajos ingresos, mientras que el tráfico de personas y drogas, tanto como un proceso corrupto de privatización, beneficiaron a las élites gubernamentales, particularmente a los militares y fuerzas de seguridad. ${ }^{6}$ En el Cáucaso, muchas mujeres empobrecidas transportan pequeñas

"Lawless Rule versus Rule of Law in the Balkans," < http://www.usip.org > , basado en una CONFERENCIA "ORGANIZED CRIME AND POLITICAL EXTREMISM IN THE BALKANS," organizado por el Instituto de Paz de los Estados Unidos y el Centro para la Delincuencia Transnacional y la Corrupción, American University, 13 nov., 2001. Acezado el: 11 oct. 2004. 
cantidades de cigarrillos a través de la frontera para mantenerse. Los grupos de delincuencia organizada, en complicidad con los corruptos organismos de custodia de fronteras, transportan armas y otras mercancías valiosas (Kukchianidze; Kupatadze; Gotsiridze, 2004). En Afganistán, los agricultores cultivan amapola porque esto les asegura mayores ganancias que los cultivos tradicionales, en tanto que los caudillos locales dotan y aprovisionan a sus fuerzas con las ganancias provenientes del negocio de la droga (Baldauf, 2003).

Con tantos segmentos de la sociedad que tienen intereses personales en la perpetuación del delito, resulta muy difícil destruir las redes y, de ese modo, devolver la economía al sector formal. Diversos sectores de la economía son participantes y beneficiarios de la economía clandestina. Por ejemplo, actualmente el $40 \%$ de la economía afgana está basada en el mercado de la droga (Kuz; Athwal, 2004). Con unas ganancias relativamente altas y una incapacidad de competir en el mercado legítimo internacional, la dependencia sobre mercancías criminalizadas es asegurada. El negocio de la droga no sólo financia a los ejércitos de los cuadillos, sino también a los talibanes y redes terroristas. ${ }^{7}$

\section{EL DELITO TRANSNACIONAL Y LA ECONOMÍA}

Para finales de los años 1990, se estimó que la delincuencia transnacional, particularmente el mercado de la droga, representaba el 2\% de la economía mundial. Este porcentaje no estaba distribuido uniformemente a lo largo de la economía internacional, sino que representaba una porción mucho mayor de la economía de los países en vías de desarrollo que de los países desarrollados. Sin embargo, en las dos décadas pasadas, los mercados de la droga en el mundo desarrollado se han vuelto progresivamente más organizados e interconectados con el mundo en vías de desarrollo (Ruggiero, 2000).

Pese a que los mercados del mundo desarrollado y en vías de desarrollo estén cada vez más interconectados a través de la globalización, existen diferencias muy importantes en las perspectivas financieras de los viejos y nuevos grupos de delincuencia organizada. Estas distintas perspectivas económicas tienen, a su vez, un impacto profundo en las relaciones entre la delincuencia organizada y el terrorismo.

Los grupos de delincuencia transnacional de mayor data han sobrevivido porque tienen una perspectiva de ganancias y sustentabilidad a largo plazo. Aún cuando comercian con la droga, la cual les ha proporcionado enormes ganancias, estos grupos han diversificado sus inversiones. Por ejemplo, la mafia italiana se enriqueció enormemente como resultado del comercio global de droga en los años 1980, pero ha invertido esas ganancias en bienes turísticos, comerciales y en propiedades agrícolas (Arlacchi, 1986). De manera similar, habiendo hecho sus ganancias con la dro-

Cuadro 1- El delito transnacional y el Estado

\begin{tabular}{l|l|l}
\hline & \multicolumn{1}{|c|}{ Delincuencia organizada tradicional } & Nueva delincuencia transnacional \\
\hline $\begin{array}{l}\text { Actitud hacia el } \\
\text { Estado }\end{array}$ & Frecuentemente nacionalista & Sus intereses no coinciden con los del Estado \\
\hline $\begin{array}{l}\text { Relación con el } \\
\text { Estado-Nación }\end{array}$ & $\begin{array}{l}\text { Crece con el Estado. Es parasitario del } \\
\text { Estado-Nación. Depende del Estado para los } \\
\text { contratos y servicios }\end{array}$ & $\begin{array}{l}\text { Florece bajo la ausencia de gobernabilidad } \\
\text { efectiva. Crece con un Estado debilitado }\end{array}$ \\
\hline $\begin{array}{l}\text { Relación con la } \\
\text { Corrupción }\end{array}$ & $\begin{array}{l}\text { Es una herramienta utilizada para } \\
\text { influenciar a los oficiales del Estado- } \\
\text { herramienta operativa }\end{array}$ & $\begin{array}{l}\text { Depende de altos niveles de corrupción } \\
\text { sistémica e institucionalizada }\end{array}$ \\
\hline $\begin{array}{l}\text { Relación con } \\
\text { el Terrorismo }\end{array}$ & $\begin{array}{l}\text { Usualmente rechaza la asociación con } \\
\text { terroristas }\end{array}$ & Puede buscar nexos con los terroristas \\
\hline
\end{tabular}

${ }^{7}$ Véase: Ministro de Defensa Francés, Michele Alliot-Marie (2004, p. A27). 
ga, la mafia colombiana se expandió hacia el negocio con fincas ganaderas y bienes inmobiliarios comerciales en Colombia, entre otros sectores de la economía legítima. Estos grupos han combinado sus inversiones en la economía legítima e ilegitima para asegurar la diversificación y la estabilidad a largo plazo (Lee III, 1990, p. 40). Muchas veces, reingresan una parte de sus utilidades a su país, del mismo modo en que guardan dinero en refugios en el exterior, frecuentemente utilizando los servicios de profesionales en el lavado de dinero, quienes, como profesionales de alto estatus, son capaces de ocultar sus ganancias e inversiones.

Existe un patrón financiero muy diferente entre los nuevos actores de la delincuencia transnacional. Estos tienen objetivos financieros a un plazo mucho más corto. A menudo, en las regiones en conflicto o en aquellas con conflictos paralizados, estos grupos no miran a futuro, sino que necesitan las utilidades generadas por su comercio ilegal para sus objetivos militares inmediatos. En algunos casos, utilizan las ganancias generadas por sus actividades ilegales para financiar insurgencias o terrorismo, tal como ocurre actualmente en Afganistán y en el Cáucaso. En estas regiones de conflicto, los grupos delictivos ven los negocios de manera distinta, pero igualmente los ciudadanos los ven como una fuerza principal en la gran economía clandestina. Estos grupos proveen bienes y servicios, así como el empleo, que no son proporcionados por la economía legítima. Por consiguiente, muchos ciudadanos, en las regiones pos-conflicto, no ven a los grupos de delincuencia organizada como simplemente "malos", sino como grupos que prestan servicios económicos requeridos para sus comunidades.

Estos nuevos grupos delictivos pueden comerciar tanto con mercancías legítimas como ilegítimas. Es menos probable que las utilidades de su negocio sean enviadas al exterior, como es el caso de los grupos delictivos tradicionales. En tanto sus ganancias son menores, sus necesidades son más inmediatas y están menos interesados en el costoso mantenimiento de paramilitares u otras fuerzas es- tratégicas. Por lo tanto, sus fondos no son invertidos con la intención de preservar el capital o de crecimiento a largo plazo. Estos grupos son menos propensos a interactuar con los profesionales que lavan dinero para los carteles de droga colombianos o la mafia italiana; en su lugar, utilizan redes lícitas de transferencias para movilizar el dinero desde afuera (tal es el caso de algunos grupos en los países balcánicos), o el hawala, el sistema bancario paralelo en el Medio Oriente que ayuda a transferir los fondos para las redes de distribución de drogas que operan fuera de Afganistán (Richards, 1999, p.47). Invariablemente, estos grupos tienen un contacto más limitado con las instituciones financieras y la comunidad bancaria internacional, por lo que tienen mucho menos necesidad de preservar las instituciones estatales existentes.

Cuadro 2 - Delincuencia transnacional: perspectivas financieras

\begin{tabular}{l|l|l|l}
\hline & $\begin{array}{l}\text { Perspectiva } \\
\text { Financiera }\end{array}$ & $\begin{array}{l}\text { Fuentes de } \\
\text { Ingresos }\end{array}$ & $\begin{array}{l}\text { Lavado de } \\
\text { Dinero }\end{array}$ \\
\hline $\begin{array}{l}\text { Delincuencia } \\
\text { Organizada } \\
\text { Tradicional }\end{array}$ & $\begin{array}{l}\text { Superviven- } \\
\text { cia a largo } \\
\text { plazo }\end{array}$ & $\begin{array}{l}\text { Economía } \\
\text { legítima e } \\
\text { ilegítima }\end{array}$ & $\begin{array}{l}\text { Instituciones } \\
\text { en el exterior } \\
\text { y economía } \\
\text { doméstica }\end{array}$ \\
\hline $\begin{array}{l}\text { Nuevos } \\
\text { grupos }\end{array}$ & $\begin{array}{l}\text { Objetivos a } \\
\text { un término } \\
\text { más corto }\end{array}$ & $\begin{array}{l}\text { Primariante } \\
\text { ilegitimas }\end{array}$ & $\begin{array}{l}\text { Ganancias } \\
\text { utilizadas } \\
\text { milicias y } \\
\text { algunas } \\
\text { empleadas } \\
\text { en la } \\
\text { inversión }\end{array}$ \\
\hline
\end{tabular}

\section{LA DELINCUENCIA TRANSNACIONAL Y LAS NORMAS COMUNITARIAS}

Los grupos tradicionales de delincuencia organizada, debido a su longevidad dentro de las comunidades, generalmente han establecido vínculos familiares y redes sociales. Tienden a apoyar la estabilidad, pues continúan viviendo dentro de las comunidades en las cuales operan; por ejemplo, los grupos chinos de delincuencia organizada, que trafican con seres humanos, necesitan garantizar una entrega segura de los individuos para cuya movilización fueron contratados, para así asegurarse de que otros en la comunidad continuarán pagan- 
do sus servicios. La mafia italiana también opera bajo las normas de la comunidad siciliana (Di Mari; Lavanco, 1995). La mafia italiana fue objeto de persecución judicial cuando los asesinatos y violencia producida por éstos provocaron que algunos de sus miembros se convirtieran en pentiti, ${ }^{8}$ o informantes del Estado. Por ejemplo, Tommaso Buscetta se volvió enemigo de Toto Riina, jefe de la mafia, después de que éste ordenó el asesinato de casi 30 miembros de la familia Buscetta. Los japoneses Yakuza también han trabajado íntimamente con la policía japonesa para mantener el orden en sus comunidades, un valor preciado dentro de la sociedad japonesa. Adicionalmente, éstos pueden tratar de congraciarse con la comunidad a través de la construcción de escuelas, hospitales y el subsidio de actividades deportivas, proporcionando, en efecto, los servicios que el Estado falló en proporcionar. Este fue el caso en Colombia con los narcotraficantes, quienes se convirtieron en importantes filántropos dentro de la comunidad. De manera similar, los Yakuza proporcionaron gran ayuda a la ciudadanía después del terremoto de Kobe.

Como se mencionó anteriormente, los nuevos grupos de delincuencia transnacional prosperan en medios donde han existido conflictos por largos períodos. Estos conflictos destruyeron familias, normas comunitarias y comunidades establecidas. Como consecuencia, los grupos delictivos funcionan de modo distinto en esas sociedades. Estos grupos no se interesan por la preservación de sus propias comunidades en la misma medida en que lo hacen los grupos delictivos tradicionales. En los países balcánicos, las mujeres con quienes los grupos del crimen kosovares albaneses trafican para trabajar en burdeles, en Europa Occidental, provienen de sus propias comunidades. Igualmente, los grupos delictivos en la región del Cáucaso, que trafican armas y drogas, han llevado a la proliferación del

${ }^{8}$ La palabra plural en italiano pentiti (pentito en inglés) es comúnmente utilizada para referir a los exmiembros de la mafia italiana, quienes han abandonado su organización y posteriormente contribuido con las investigaciones (Nota del Traductor). abuso de drogas y la violencia en su región. Por ejemplo, el reciente y trágico acto terrorista ocurrido en una escuela en Beslan, Ingushetia, fue liderado por un ex oficial de la policía de ese país, quien se había aliado con los rebeldes chechenos.

Por consiguiente, los valores normativos no constriñen a los nuevos grupos de delincuencia organizada en la misma medida en que constriñen a los grupos delictivos más tradicionales. Esta afirmación puede parecer extraña cuando se considera el daño social generado por los grupos delictivos tradicionales. Sin embargo, su deseo por perpetuarse a sí mismos significa que éstos sean menos propensos a violar los derechos humanos de los miembros de sus comunidades o a establecer vínculos altamente destructivos con terroristas. ${ }^{9}$

\section{CONCLUSIONES: los nuevos actores delictivos transnacionales y el terrorismo}

La planificación de los sucesos del 11 de Septiembre de 2001 se llevó a cabo en Hamburgo, Alemania. Los terroristas que accionaron las bombas en los trenes en Madrid en Marzo de 2004 se mantenían a través del delito. Los contrabandistas chinos conocidos como snakeheads (cabezas de culebra) han desarrollado relaciones de protección y comercio con el Ejército Republicano Irlandés. Los vínculos peligrosos de los nuevos grupos de delincuencia transnacional no tienen lugar únicamente en los países en vías de desarrollo y en transición, sin embargo, en las regiones que carecen de instituciones estatales fuertes, la combinación entre este tipo de delincuencia y el terrorismo asume su forma más potente.

Los nuevos actores de la delincuencia transnacional necesitan del Estado y de la economía global establecida mucho menos que los grupos delictivos tradicionales. Dado que tienen objetivos de supervivencia a corto plazo, sus intereses ${ }^{9}$ Por ejemplo, con respecto a la diferencia entre el tráfico
de humanos fuera de China, Rusia y los países balcánicos
y las razones por las cuales estos abusos son más seve-
ros en los últimos dos escenarios, véase mi artículo
anterior: Shelley (2003, p.119-131 e Ruggiero, 2000). 
no convergen con los de aquellos interesados en la construcción del Estado, ni con el mantenimiento del sistema financiero internacional existente. La caída de las bolsas de valores, en respuesta a los actos terroristas, o el declive del turismo en Bali y en El Sinaí, no preocupan a estos nuevos grupos delictivos, pues, a diferencia de los grupos tradicionales, estos no han lavado su dinero en acciones o complejos vacacionales. $\mathrm{Su}$ razonamiento político es muy distinto del de los grupos delictivos establecidos, quienes, por sus inversiones a gran escala, imitan a sus homólogos legítimos en busca de estabilidad financiera internacional para asegurar sus inversiones.

Las regiones donde convergen los grupos de delincuencia transnacional y los terroristas, particularmente la región tri fronteriza en América Latina, los países balcánicos, el Cáucaso, las zonas en conflicto de África Occidental y Afganistán, han proporcionado un refugio seguro para el fomento del terrorismo y sus operaciones. Pese a que estas regiones no tienen un monopolio de tales actividades, han asumido un rol central en la inseguridad internacional.

El cruce entre el delito transnacional y el terrorismo es más viable en las regiones con grandes economías subterráneas. En estas regiones, las actividades ilegítimas de ambos grupos son menos visibles. El financiamiento del terrorismo a través de la actividad delictiva es el menos riesgoso y la extensión y magnitud de la colaboración es más pronunciada.

El vínculo desestabilizador entre el delito transnacional y el terrorismo ha resultado tan difícil de atacar porque los planificadores de las políticas continúan concibiendo el delito en términos de los paradigmas tradicionales. La divergencia entre las políticas deEstados Unidos y Europa, observada con mayor visibilidad en lo referente a la guerra en Irak, también está muy evidente en el terreno de las respuestas gubernamentales frente a la delincuencia transnacional. Los encargados de formular las políticas estadounidenses, en un mundo pos 11 de septiembre, han focalizado casi exclusivamente en el terrorismo, mientras que sus homólogos europeos han prestado mucha más atención a la delincuencia transnacional. Ninguno de estos planificadores está empleando el pensamiento integrador que se requiere para este nuevo desafío.

(Recebido para publicação em novembro de 2006) (Aceito em abril de 2007)

\section{REFERÊNCIAS}

ABADINSKY, Woward. Organized crime. 6.ed. Belmont, CA: Wadsworth, 2002. p. 246-247.

ADDULLAEV, Nabi. Kremlin unarmed as chechen rebels strengthen. Eurasia Daily Monitor, jul., 2004.

ALLIOT-MARIE, Michelle. Afghanista's drug boom. Washington Post, 6 oct. 2004, p. A27.

ANDREAS, Peter. Transnational crime and corruption in the Balkans. Problems of Post-Communism. [S.1.], v. 51, n. 3 mayo/jun., 2004.

ARLACCHI, Pino. Mafia business: the mafia ethic and the spirit of capitalism. London: Verso, 1986.

BALDAUF, Scott. Afghan military tied to drug trade. Christian Science Monitor, 4 sept. 2003.

BALES, Kevin. Disposable people: new slavery in the global economy. Berkeley: University of California Press, 2000.

BERDAL, Mats; MALONE, David M. Greed \& Grievance: economic agendas in civil wars. Boulder, CO: Lynne Rienner Publishers, 2000.

BOOTH, Martin. The Dragon Syndicates: the global phenomenon of the triads. New York: Carroll and Graf, 1999. p. 17-27

CAMPBELL, Greg. Blood diamonds: tracing the deadly path of the world's most precious stone. Boulder, CO: Westview, 2002.

CATANZARO, Raimondo. Men of respect: a social history of the Sicilian Mafia. New York: Free Press, 1992.

DELLA PORTA, Donatella. Lo scambio occulto casi di corruzione política in Italia. Bologna: II Mulino, 1992. p. 312-328.

DI MARI, Franco; LAVANCO, Gioacchino. A un passo dall'inferno. Sentire mafioso e obbedienza criminale. Firenze: Giunti, 1995.

KAPLAN, David E.; DUBRO, Alec. Yakuza: Japan's criminal underworld. Berkeley: University of California Press, 2003.

KUKHIANIDZE, Alexandre; KUPATADZE, Alexandre; GOTSIRIDZE, Roman. Smuggling through Abkhazia and Tskhivali Region of Georgia. < http://www.traccc.cdn.ge/ publications/index.html >. Acezado el: 11 oct. 2004.

KUZ, Dennis; ATHWAL, Harpinder. Afghan progress undermined by drugs. <http://www.csmonitor.com $>$. Acezado el: 08 oct., 2004.

LEE III, Rensselaer W. The white labyrinth cocaine and political power. New Brunswick: Transaction, 1990. p. 40.

McC. HEYMAN, Josiah; SMART, Alan. States and illegal practices: an overview. In: (Eds.) States and illegal practices. Oxford; New York: Berg, 1999. p. 1-24. 
NAYLOR, R. T. Wages of crime: black markets, illegal finance and the underworld economy. Ithaca, NY: Cornell University Press, 2002.

PEZZINO, Paolo. Una certa reciprocita di favori mafia e modernizzazione violenta nella Sicilia postunitaria. Milano: Franco Angeli, 1990

RENO, William. Shadow states and the political economy of civil wars. En: BERDAL, Mats; MALONE, David M. Greed \& Grievance: economic agendas in civil wars. Boulder, CO: Lynne Rienner Publishers, 2000.

REUTER, Peter. The decline of the american mafia. The Public Interest. [S.1.], p, 89-99, summer, 1995.

Promotion of measures against organized crime groups. National Police Agency, Government of Japan, p.54-61, 1995; (Reimp.) en Trends in Organized Crime v. 1, n. 3, p. 49-57, spring, 1996.

ATRINDADE NÃO SANTA: deliqüência transnacional, corrupção e terrorismo

Louise Shelley

Os tradicionais grupos de delinqüência transnacional e seus rentes com o Estado e com o terroris- with the State and with terrorism. In mo. Em países formados há muito long stablished countries, the more tempo,os grupos delitivos de maior ancient criminal groups were antigüidade têm se desenvolvido jun- developed along the state organs and to aos órgãos estatais e dependem das depend on the existent institutional estruturas institucionais e financeiras and existentes para movimentar seus produtos e investir seus ganhos. Estes gruThese groups also require stable pos também requerem comunidades communities and frequently try to estáveis e com freqüência tentam com contribute to them, while rejecting elas contribuir, ao tempo que repudi- any contact with terrorist groups. The am qualquer contato com grupos more recent groups of transnational terroristas.Os grupos mais recentes de delinquency have often their origins delinqüência transnacional, in post-conflict situations, where freqüentemente, têm sua origem em there can still be a state of chaos: they situações pós-conflito, onde ainda are the actors that dominate the pode haver um estado de caos, são os clandestine economy. These new atores que dominam a economia clan- groups generate alliances with destina. Estes novos grupos geram ali- terr anças com organizações terroristas of porque nenhum dos dois possui estratégias financeiras nem horizontes políticos a longo prazo. A vinculação desestabilizadora entre o delito transnacional e o terrorismo tem resultado tão difícil de atacar porque os planejadores das políticas continuam paradigmas tradicionais.

Palavras-chave: delinqüência, Keywords: delinquency, transtransna-cional, corrupção, terroris- national corruption, terrorism. mo.

Louise Shelley - Doutora em Sociologia na University of Pennsylvania e Mestre em criminologia. Formada em penologia e literatura russa na Cornell University. Professora do Departamento de Justiça, Lei e Sociedade (Escola de Assuntos Públicos) e da School of International Service, da American University em Washington, DC. Fundadora e diretora do Centro de Estudos sobre Terrorismo, Crime Transnacional e Corrupção (TraCCC). Autora de muitos livros, artigos e capítulos de livros sobre criminalidade transnacional, conexões entre crime e terrorismo e padrões de criminalidades nos ex-países socialistas. Foi bolsista da Guggenheim, Fulbright, NEH, IREX e do Kennan Institute fellowships.
LA TRINITE PAS SAINTE: délinquance transnationale, corruption et terrorisme

\section{Louise Shelley}

Les groupes traditionnels de délinquance transnationale et leurs homologues plus récemment formés ont des relations bien différentes avec l'Etat et le terrorisme. Dans des pays ormés depuis plus longtemps, les développent auprès plus anciens se étatiques et dépendent des structures institutionelles et financières existantes pour actionner leurs produits et investir leurs gains. Ces groupes ont aussi besoin de communautés stables et essaient de leur rejettent tous contacts avec les groupes terroristes. Les groupes plus récents de délinquance transnationale trouvent souvent leur origine dans des situations postérieures aux conflits où il existe encore un état de chaos. Ce sont eux font des alliances avec des organisations terroristes parce que ni les uns ni les autres ne possèdent de stratégies financières ou d'horizons politiques à long terme. Le résultat du lien déséquilibrant existant entre le délit transnational et le terrorisme est très difficile à vaincre parce que ceux qui planifient les politiques considèrent toujours le délit en termes de paradigmes traditionnels.

Mots-CLÉs: délinquance, transnational, corruption et terrorisme. 